\title{
Impaired corrective responses to postural perturbations of the arm in individuals with subacute stroke
}

\author{
Teige C Bourke ${ }^{1}$, Angela M Coderre ${ }^{1}$, Stephen D Bagg ${ }^{2}$, Sean P Dukelow ${ }^{3}$, Kathleen E Norman ${ }^{4}$
} and Stephen $\mathrm{H}$ Scott ${ }^{1,5^{*}}$

\begin{abstract}
Background: Stroke is known to alter muscle stretch responses following a perturbation, but little is known about the behavioural consequences of these altered feedback responses. Characterizing impairments in people with stroke in their interactions with the external environment may lead to better long term outcomes. This information can inform therapists about rehabilitation targets and help subjects with stroke avoid injury when moving in the world.

Methods: In this study, we developed a postural perturbation task to quantity upper limb function of subjects with subacute stroke $(n=38)$ and non-disabled controls $(n=74)$ to make rapid corrective responses with the arm. Subjects were instructed to maintain their hand at a target before and after a mechanical load was applied to the limb. Visual feedback of the hand was removed for half of the trials at perturbation onset. A number of parameters quantified subject performance, and impairment in performance was defined as outside the 95th percentile performance of control subjects.

Results: Individual subjects with stroke showed increased postural instability (44\%), delayed motor responses (79\%), delayed returns towards the spatial target (79\%), and greater endpoint errors (74\%). Several subjects also showed impairments in the temporal coordination of the elbow and shoulder joints when responding to the perturbation (47\%). Interestingly, impairments in task parameters were often found for both arms of individual subjects with stroke (up to $58 \%$ for return time). Visual feedback did not improve performance on task parameters except for decreasing endpoint error for all subjects. Significant correlations between task performance and clinical measures were dependent on the arm assessed.
\end{abstract}

Conclusions: This study used a simple postural perturbation task to highlight that subjects with stroke commonly have difficulties responding to mechanical disturbances that may have important implications for their ability to perform daily activities.

Keywords: Stroke, Proprioception, Assessment, Perturbation, Upper limb, Robotics

\section{Background}

When holding a drink in a crowded room and someone bumps your arm, you must rapidly respond to keep the drink from spilling. Recent studies highlight that the motor system is capable of generating intelligent corrective responses to unexpected forces applied to the body

\footnotetext{
* Correspondence: steve.scott@queensu.ca

'Centre for Neuroscience Studies, Queen's University, Kingston, ON, Canada ${ }^{5}$ Department of Biomedical and Molecular Sciences, Queen's University, Kingston, ON, Canada

Full list of author information is available at the end of the article
}

$[1,2]$. For example, perturbation responses have been shown to account for subject intent [3-7], urgency to respond [8], properties of the limb [9] and properties of the goal and environment $[10,11]$. These task-related responses can be observed in the long-latency time period, $\sim 50 \mathrm{~ms}$ after perturbation onset, implying these responses are generated through a transcortical feedback pathway [12-14]. Historically, the transcortical feedback pathway is considered to involve primary motor and somatosensory cortices [15-17], but many other cortical 
and subcortical areas may contribute to these corrective responses [2].

Stroke can damage cortical and subcortical regions of the brain or spinal cord, leading to a wide range of sensory and/or motor impairments [18]. This damage often leads to patients having slow, jerky and uncoordinated movements post-stroke [19]. The impact of stroke on corrective responses in the upper limb has principally been explored by quantifying long latency stretch responses in muscles. In stroke, long-latency responses have been found to be delayed and/or absent in wrist muscles [20] and the biceps brachii [21]. Subjects with stroke do not modulate their long latency responses when their arms counter stiff versus compliant environments [10] and also display inappropriate coupling between different muscle groups [22].

Only a few of the aforementioned studies that quantified changes in long-latency stretch responses in the upper limb also examined behavioural responses to perturbations [14,19]. Many perturbation studies were designed to assess spasticity and instructed subjects to relax and not intervene or react to the perturbation [14,19,23-25]. Other studies have instructed subjects to actively assist [26] or actively resist [27] the perturbation. In these paradigms the applied perturbation directly controlled limb motion so that the subject could not actively achieve the behavioural goal. Therefore, it is difficult to interpret the subjects' behavioural impairments without an attainable goal [2].

Previous studies also highlight potential deficits in the ipsilesional arm post-stroke. For example, subjects with stroke have shown bilateral impairments in modulating long latency responses between stiff and compliant environments [10]. Marsden and colleagues also found that 5 out of 12 subjects with stroke had reduced long latency responses in the both arms [15]. Again, it is not clear how altered long-latency responses in the ispilesional limb are linked to behavioural impairments for these individuals.

Finally, vision plays an important role in voluntary motor control and could provide an important alternate source for correcting limb disturbances when somatosensory feedback is impaired. Bonan and colleagues found that visual feedback was critical for maintaining whole-body posture [28]. Piovesan and colleagues found arm stiffness was reduced during reaching when poststroke subjects used visual feedback [29]. However, little is known on the relative contribution of visual and somatosensory feedback to counter limb perturbations [30]. Visual feedback is slower than limb somatosensory feedback. Thus it is predicted that impairments in somatosensory feedback can be compensated for by visual feedback except for a slight delay in the corrective response.
Our goal was to create a behavioural task to quantify the ability of subjects with stroke to actively correct for unexpected disturbances of the arm during a goaldirected motor action. Subjects had to maintain their hand at a spatial goal and a constant load was applied to the limb so that subjects must respond to the disturbance to achieve the behavioural goal [2]. Corrective responses were assessed in both the contra- and ipsilesional arms. As well, we examined corrective responses with and without vision to quantify whether impairments in the use of somatosensory feedback could be compensated for with vision. Subjects with stroke were often slower than controls in decelerating the arm in response to the imposed load, took longer to return to the goal or undershot the target. Endpoint error was the only parameter that showed improvement when visual feedback was provided to subjects. About half of subjects with stroke who showed task impairments with their more affected arm also showed impairments with their other arm. Thus, this robotic postural perturbation task quantifies post-stroke impairments in the use of limb afferent feedback to generate motor corrections.

\section{Methods}

\section{Subject information}

Participants with stroke were recruited from three inpatient stroke rehabilitation programs: Providence Care (St. Mary's of the Lake Hospital, Kingston, ON), Dr. Vernon Fanning Centre (Calgary, $\mathrm{AB}$ ) and Foothills Hospital (Calgary, AB). Subjects potentially eligible to participate were assessed 2-50 days post-stroke usually within 2 weeks of being admitted to rehabilitation programs at each centre. Prospective subjects were excluded if they had bilateral lesions, previously diagnosed strokes, other neurologic diagnoses (e.g. Parkinson's disease), ongoing upper extremity musculoskeletal injuries, or an acute medical illness. Non-disabled control subjects were recruited from the local Kingston, ON community. All subjects were able to understand the instructions required to complete the task, were able to see the visual target, and provided informed consent. This study was approved by the Queen's University Health Sciences and Affiliated Teaching Hospitals Research Ethics Board (\#ANAT042-05), and the University of Calgary's Conjoint Health Research Ethics Board (\#22123).

\section{Clinical assessments}

Subjects with stroke were evaluated using a number of standardized clinical assessments. Upper limb physical impairments were measured using the Chedoke-McMaster Stroke Assessment (CMSA) impairment inventory for the arm [31]. In this scale, impairment is measured on a seven-point scale based on Brunnstrom's stages of motor recovery [32]. Subjects received a minimum score of one 
for flaccid paralysis and maximum score of seven for normal voluntary movement control. Subject strength was also measured for elbow and shoulder flexion and extension using the muscle power assessment [33]. Each muscle group (shoulder and elbow) was scored from no visible or palpable contraction (0) to normal volitional isometric strength (5), for a total composite score of 20 for upper limb strength. Functional abilities were measured by the Functional Independence Measure (FIM) [34]. The FIM scores the amount of assistance $(1=$ total assistance, $7=$ total independence) required to achieve different activities of daily living, and can be divided into cognitive and motor subsections. The conventional subtests of the Behavioural Inattention Test (BIT) were used to screen for deficits of attention/neglect with a score of less than 130/ 146 indicative of visual neglect [35]. Subjects were broadly categorized as "Left-Affected" (LA) or "Right-Affected" (RA) depending on the clinically most affected side of the body. All subjects took the Modified Edinburgh Handedness test to determine handedness [36].

\section{Experimental setup}

The experimental assessment was implemented using a bilateral KINARM exoskeleton device (BKIN Technologies Ltd, Kingston, ON, Canada). Subjects sat in a modified wheelchair base and their forearms and upper arms were fitted snugly to plastic arm troughs that were attached to an adjustable four bar linkage [37,38]. Linkage lengths were adjusted to the dimensions of the subject's arms, permitting free movement of the elbow and shoulder joints in the horizontal plane. The exoskeleton supported the weight of the subject's arms against gravity and was used to apply mechanical loads to the elbow or shoulder joint. Subjects were wheeled into an augmented reality system that displayed virtual targets in the same plane as arm motion. Direct vision of the subject's arms was occluded. Visual feedback, by means of a white dot at the location of the subject's index fingertip position, was provided.

Position and velocity of the robot was recorded at a sampling rate of $1000 \mathrm{~Hz}$. Subject joint angles and velocities, and hand position, speed, and acceleration were calculated from these values. Hand and joint-based signals were analyzed using MATLAB (Mathworks Inc., Massachusetts). Signals were filtered using a sixth-order double-pass Butterworth low pass filter with a cutoff frequency of $10 \mathrm{~Hz}$.

\section{Experimental task}

Subjects were assessed in an upper limb postural perturbation task. In each trial, subjects were required to maintain their hand at a virtual target. After a random delay of 1750 to $2250 \mathrm{~ms}$, subjects received a flexor or extensor step torque to the elbow $(+/-0.5 \mathrm{Nm})$ or shoulder $(+/-1 \mathrm{Nm})$. Subjects were instructed to return their hand to the target as soon as they felt the robot 'bump' them. The perturbation torque remained constant during the duration of the trial (3 seconds). A step torque was chosen to ensure subjects could not simply co-contract their muscles to respond to the perturbation. As well, the sustained torque allowed for the full unfolding of long-latency and voluntary motor responses to the perturbation which would have otherwise been quenched within $30 \mathrm{~ms}$ of perturbation offset [2,39]. This meant subjects needed to actively increase muscle activity to oppose the load to bring the hand back to the target. The task was divided into 9 blocks of 8 trials each. Each block contained two trials of each of the four perturbation conditions (flexion and extension of the shoulder and elbow). In the first block (not used in analyses), subjects were able to practice with visual feedback of the fingertip position. Subsequently, visual feedback of fingertip position was removed at perturbation onset in half of the trials in each block. The order of trials was randomized within each block. Subjects completed the task with one arm (chosen at random) before completing it with the other arm.

A subset of subjects $(n=11$, subjects with stroke; $n=6$ controls) completed inter-rater reliability testing of the postural perturbation task. After their first assessment was completed, the subject was taken out of the chair and all adjustments to the KINARM robot were modified (e.g. seat height, arm length, calibration of video display). At this time, a second operator, not present for the initial assessment, set up the subject in the device and reassessed the same subject. The second assessment of the subject usually occurred immediately following the first assessment and at most 7 days from the original assessment. This second operator had no knowledge of the previous subject specific adjustments.

\section{Task performance measures}

Posture speed- The 95th percentile of the median hand speed for the $500 \mathrm{~ms}$ before perturbation onset (Figure 1a). Increased postural speed indicated increased difficulty maintaining the fingertip within the visual target.

Deceleration time- The time it took subjects to reach the first minimum hand speed after perturbation onset (Figure 1a). Deceleration time quantified how soon subjects responded to the perturbation and opposed the imposed load enough to slow their arm. The acceleration time (time to first hand speed maxima) could also have been used to quantify the time to respond to the perturbation, but was highly correlated to deceleration time $\left(\mathrm{r}=0.90, \mathrm{p}<10^{-27}\right)$ and less sensitive to stroke-related impairments.

Return time- The time required for subjects to return to within $1 \mathrm{~cm}$ of their position at the end of the trial 

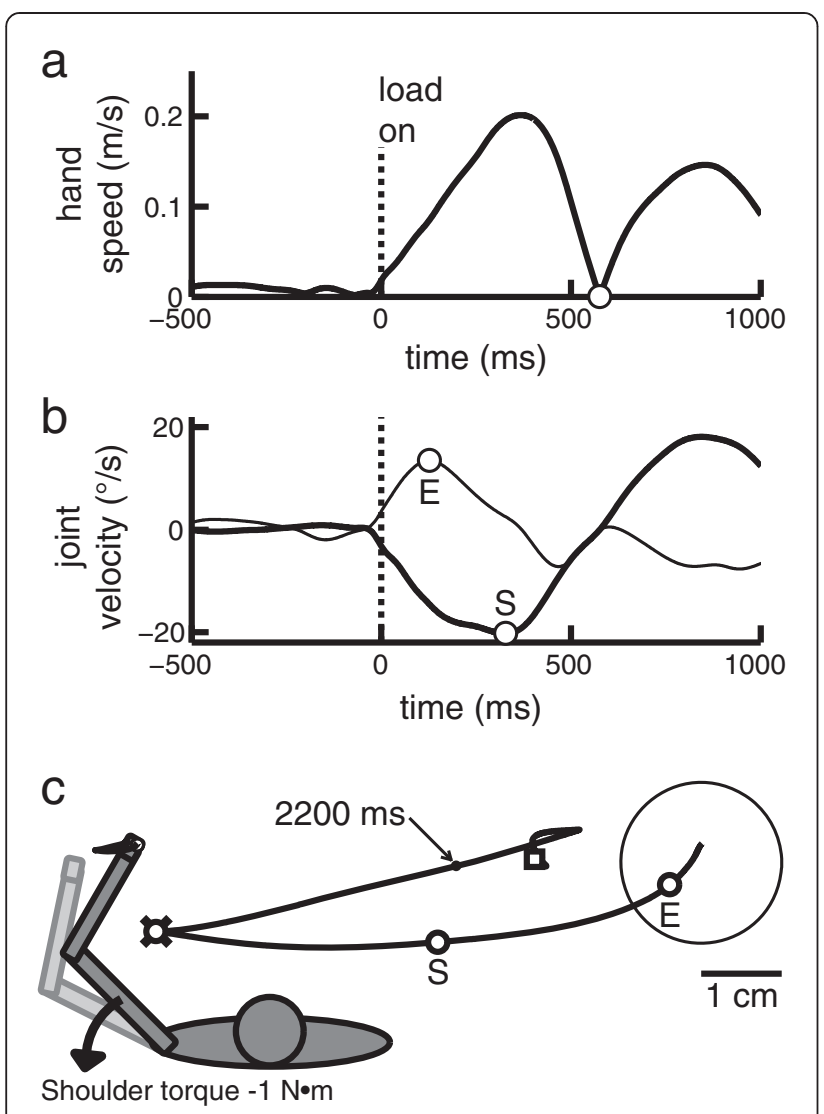

Figure 1 Exemplar trial where the left arm is responding to being perturbed into shoulder extension. (a) Hand speed over time. Hand speed minimum representing the end of the hand's initial deceleration is shown by the circle marker. (b) Joint velocity of the loaded joint (shoulder, thick line) and the non-loaded joint (elbow, thin line) over time. Joint flexion is positive and joint extension is negative. The initial velocity extrema of the elbow and shoulder joint are marked by the circle markers, labelled ' $E$ ' and ' $S$ ' respectively. The offset is the time between these points. (c) Left: Schematic of arm orientation and perturbation direction for the trial presented in this figure. Right: Participant's hand path after perturbation onset. The visual target and the hand path are shown in black. The initial velocity extrema of the elbow and shoulder joint are marked by the circle markers, labelled ' $E$ ' and 'S' respectively. The X marker indicates the maximum displacement of the hand (which in this case corresponded to the deceleration time- circle marker). Return time occurred when subject returned within $1 \mathrm{~cm}$ of their endpoint location (dot marker indicated to occur at $2200 \mathrm{~ms}$ ). Endpoint (the position at the end of the trial) is indicated by square marker and endpoint error is the distance between this point and the centre of the visual target.

(Figure 1c). This indicated how quickly subjects took to complete their corrective response within the 3 seconds time limit.

Endpoint error- The distance from the target centre at the end of the trial (Figure 1c). Endpoint error quantified how accurately subjects could use feedback (proprioceptive, or proprioceptive and visual) to position their hand back to the target within the 3 second time limit.
Maximum displacement- The maximum distance the subject's fingertip was pushed out of the target by the perturbation (Figure 1c). This measures how effectively subjects were able to resist the imposed load.

Joint velocity offset- The time difference between the first velocity extrema of the directly and indirectly perturbed joints. For instance, in a shoulder flexion perturbation trial, the shoulder (directly perturbed joint) may take longer to respond than the elbow (indirectly perturbed joint) (Figure 1b). Joint velocity offset was used as an indicator of the timing of multi-joint coordination while responding to the perturbation.

\section{Statistical analysis}

The mean performance of control subjects was used to create a normative reference range for each parameter [40]. This range was used to characterize each individual stroke subject as impaired on a given parameter if they had mean performance greater than $95 \%$ of control subjects. From the distribution of mean control performance, linear regressions were used to determine if there was any effect of age or body weight. Regression residuals were tested for normality (Lilliefors test, $\mathrm{p}<0.05$ ). If residuals were not normally distributed, logarithmic, square root, inverse or exponential transforms of the original data were used to attempt to obtain a linear regression with normally distributed residuals. The linear regression was then transformed back into native values and used to create a normative model. A two-tailed Kolmogrov-Smirnov test (KS test) was used to determine if there was any effect of hand dominance or sex.

If the residual distribution could not be transformed to a normal distribution, a Wilcoxon Rank Sum $(\mathrm{p}<0.05)$ of the original data was used to determine if these factors had any significant effect. Control data were then binned into three different ranges of age or body weight (depending on the effect) and separate percentiles for each bin created the normative model. A rank sum test was then used to determine if there was any effect of hand dominance or sex.

The 95th percentile of control performance was used to characterize an individual stroke subject as impaired in a given parameter. If performance of a control was outside the 99.9th percentile for a single parameter, the subject's data were excluded for all parameters. If a parameter could not be transformed to have normally distributed control performance, the threshold for exclusion was $2 \mathrm{x}$ the 95th percentile. This exclusion step identified control subjects who were outliers in any of the 6 task parameters. After each exclusion of an outlier, the threshold percentiles for exclusion were re-calculated and any new outliers were identified and excluded. This process continued until no further outliers could be identified. In total, 13 control subjects were excluded from further analysis. 


\section{Results}

\section{Subject demographics and clinical measures}

Demographic and clinical information about the subjects are provided in Table 1 . Thirty eight subjects with subacute stroke completed the perturbation task. All subjects had an ischemic stroke except for one subject who had a left hemisphere hemorrhagic stroke. Our group of subjects with stroke displayed a broad range of FIM scores (37-126), but a median score of 107 indicated many subjects had mild disability (108 for LA subjects and 107 for RA subjects). Five subjects with stroke had a BIT score of less than 130 indicative of neglect, and 8 subjects had visual field deficits (3 with hemianopsia, 1 quandrantanopia, 3 peripheral vision loss, and 1 smaller scotoma). Stroke subjects' CMSA arm scores ranged from 2-7 for the affected arm and 5-7 for the unaffected arm.

Eighty-seven controls were also assessed in the postural perturbation task, of which 74 met the criteria for retention (see Methods- Statistical Analysis). Subjects were specifically selected to span a broad range of ages in order to develop age normative models (see Methods- Statistical Analysis). The control group was similar to the group of subjects with stroke in its proportions for sex (controls: $57 \%$ male, subjects with stroke: $55 \%$ male) and reported hand dominance (controls: $92 \%$ right hand dominant, subjects with stroke: $82 \%$ right hand dominant).

\section{Task results without visual feedback of hand position Exemplar subjects}

The left panels of Figure 2 displays perturbation responses of an 83 year old female control subject who was right handed. Performance is shown for the left arm for trials where vision of the hand is removed at the start of the perturbation. Hand motion was minimal following perturbations (mean maximum displacement: $3.85 \mathrm{~cm}$ ) and the subject's hand was, on average, within $1.32 \mathrm{~cm}$ of the centre of the target at the end of the trial (mean return time: $1051 \mathrm{~ms}$ ) (Figure 2a). Posture speed for this subject was $0.84 \mathrm{~cm} / \mathrm{s}$. Figure $2 \mathrm{~b}$ displays hand speed when shoulder extensor loads were applied. Initial hand speed profiles display a similar first peak and first minima, highlighting that the subject generated a consistent rapid motor response to stop hand motion at 300 ms following the shoulder perturbation. Beyond this time, speed profiles are more idiosyncratic when returning and maintaining their hand within the spatial target. Shoulder and elbow velocity also followed a consistent pattern when this shoulder extension perturbation was applied, with the elbow flexor velocity first peaking at $\sim 100-200 \mathrm{~ms}$ followed by the shoulder extensor velocity peaking at $\sim 150-250 \mathrm{~ms}$ (Figure $2 \mathrm{c}$ ).

The right panel of Figure 2 displays perturbation responses from the left affected arm of an 80 year old female measured 27 days post stroke. This subject was right handed, had a FIM motor subscore of 68/91, and scored $6 / 7$ on the CMSA arm subscale with their left arm. The hand of the subject with stroke was displaced $11.90 \mathrm{~cm}$ (on average) outside the target (Figure 2a) by the perturbation. This subject took much longer to return (mean return time: $2380 \mathrm{~ms}$ ) than the control subject, and often ended the trial short of the target resulting in average endpoint errors of $1.84 \mathrm{~cm}$ (Figure 2a). Postural hand speed was also greater for this subject at $1.30 \mathrm{~cm} / \mathrm{s}$. The first hand speed peaks and minima of this subject with stroke were later and more variable than the control subject, highlighting the difficulty in stopping her hand against the imposed load (Figure 2b). The first elbow

Table 1 Clinical and demographic information of included subjects

\begin{tabular}{|c|c|c|c|c|}
\hline Measure & Subjects with Stroke $(n=38)$ & Left-Affected $(n=22)$ & Right-Affected $(n=16)$ & Controls $(n=74)$ \\
\hline Age (years) $)^{a}$ & $63.5(26-87)$ & $65.5(26-83)$ & $62(41-87)$ & $47.5(20-87)$ \\
\hline Weight $(\mathrm{kg})^{\mathrm{a}}$ & $85.2(55-127)$ & $85.2(55-127)$ & $85.4(59-127)$ & $75(45.5-134)$ \\
\hline $\operatorname{Sex}(M / F)$ & $21 / 17$ & $12 / 10$ & $9 / 7$ & $42 / 32$ \\
\hline Handedness $(L / R / A)$ & $6 / 32 / 0$ & $2 / 20 / 0$ & $4 / 12 / 0$ & $6 / 68 / 0$ \\
\hline Days since stroke ${ }^{a}$ & $27.5(2-50)$ & $22.5(2-46)$ & $31.5(12-50)$ & - \\
\hline$F M^{a b}$ & $107(37-126)$ & $108(37-124)$ & $107(66-126)$ & - \\
\hline FIM motor score $e^{a c}$ & $74.5(17-91)$ & $75.5(17-90)$ & $73.5(41-91)$ & - \\
\hline BIT score ${ }^{a}$ & $141.5(86-146)$ & $141.5(86-146)$ & $142(128-146)$ & - \\
\hline Strength ${ }^{a}$ & $16(3-20)$ & $16.5(3-20)$ & $16(4-20)$ & - \\
\hline \multicolumn{5}{|l|}{ CMSA arm score } \\
\hline Affected arm $^{d}$ & {$\left[\begin{array}{lllllllllllll}0 & 8 & 9 & 5 & 8 & 4 & 4\end{array}\right]$} & {$\left[\begin{array}{llllllllllll}0 & 4 & 4 & 2 & 7 & 3 & 2\end{array}\right]$} & 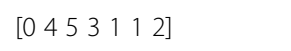 & - \\
\hline Unaffected arm ${ }^{d}$ & 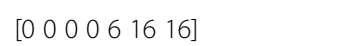 & {$\left[\begin{array}{lllllll}0 & 0 & 0 & 0 & 5 & 6 & 11\end{array}\right]$} & {$\left[\begin{array}{llllllll}0 & 0 & 0 & 0 & 1 & 1 & 0 & 5\end{array}\right]$} & - \\
\hline
\end{tabular}

Abbreviations: M/F (male/female), L/R/A (left/right/ambidextrous), FIM (Functional Independence Measure), CMSA (Chedoke-McMaster Stroke Assessment scale) Legend: ${ }^{a}$ median (min-max); ${ }^{b} \mathrm{FIM}$ consists of 18 items scored from 1 to 7 , higher scores representing greater functional independence ${ }^{\mathrm{c}}$ subset of FIM with 13 items. ${ }^{d}[n 1 n 2 n 3 n 4 n 5 n 6 n 7]$ corresponds to the number of subjects with CMSA arm scores of [1 23456 7]. A higher score represents lower physical impairment. 


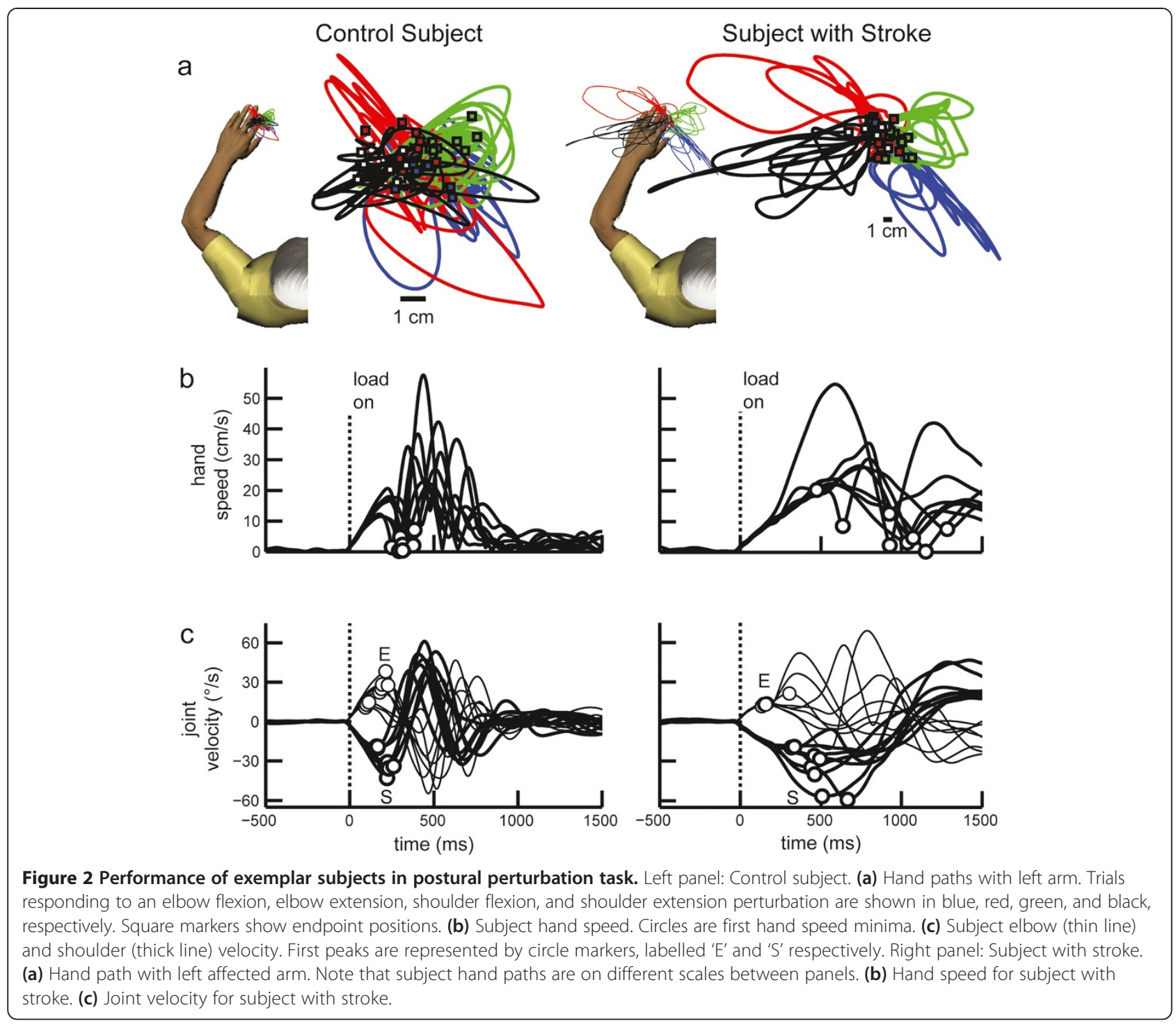

velocity peak showed similar timing to the control subject, peaking at $\sim 150 \mathrm{~ms}$ after the perturbation (Figure 2c). However, the first shoulder velocity peaks of this subject with stroke were more delayed and variable following the perturbation. This resulted in larger and more variable joint velocity offsets.

\section{Control performance}

For each parameter, the average performance of control subjects was used to quantify typical behavior. Only return time showed a significantly greater values for females as compared to males (KS test, $D=0.30, p<0.01$ ). Endpoint error significantly increased with age (linear regression, $r=0.25, p<0.01)$. Path length and joint velocity offset (elbow and shoulder perturbation conditions) significantly increased with body weight (linear regression, $r=0.25, r=0.14, r=0.36, p<0.01)$. Return time significantly increased with age for the female subgroup (linear regression, $r=0.43, p<0.01$ ). Return times also significantly decreased with body weight (i.e. heavier arms returned faster) for the female subgroup (linear regression, $r=0.37, p<0.01)$. Hand dominance had no effect on the performance of control subjects (KS test, $D<0.17, p>0.25)$ in any task parameter. Normative models were used to account for these effects and calculate the percentiles for these parameters. Subjects with stroke were identified as impaired if their performance was greater than the 95th percentile of controls.

Control subjects displayed a range of how quickly and accurately they could respond to the perturbation and return to the target without visual feedback of hand position. Control subjects maintained posture at the visual target with a mean hand speed ranging from 0.5 to $1.5 \mathrm{~cm} / \mathrm{s}$. After perturbation onset, $95 \%$ of control subjects stopped decelerating their hand in less than $400 \mathrm{~ms}$ and returned within $1 \mathrm{~cm}$ of their endpoint in less than 
1.4 seconds. Even without visual feedback of hand position, $86 \%$ of control subjects returned their hand to the target (mean endpoint error less than $1 \mathrm{~cm}$ ). After applying the age normative model, the 95th percentile of control performance ranged from $1.1 \mathrm{~cm}$ for young adults to $1.5 \mathrm{~cm}$ for older adults. Control subjects were usually displaced 1 to $4 \mathrm{~cm}$ from the target center and had a mean path length of 5-15 cm.

\section{Subjects with stroke: performance with affected limb}

Many individual subjects with stroke showed greater parameter values with their affected arm than 95\% of controls and were identified as impaired (Table 2). Interestingly, left affected (LA) subjects were impaired more frequently than right affected (RA) subjects for all parameters. For instance, $91 \%$ of left affected subjects and $63 \%$ of right affected subjects had impaired deceleration times (Figure 3a). Similarly, as compared to the age normative model, $86 \%$ of LA subjects and $56 \%$ of RA subjects had impaired endpoint errors (Figure $3 \mathrm{~b}$ ).

Although elbow and shoulder loads created significantly different responses in each task parameter for controls (KS test, $D>.39, p<10^{-4}$ ) the intra-subject values were highly correlated (controls: $p<10^{-12}, r>=0.71$, stroke: $p<10^{-7}, r>=0.74$ ). Joint velocity offset was the one parameter that was an exception to this finding (Figure 3c). In response to a shoulder perturbation, the shoulder always took longer to reach its first velocity extrema than the elbow. In response to an elbow perturbation, the elbow reached its first velocity extrema at about the same time as the shoulder (extrema were within $10 \mathrm{~ms}$ of each other for $57 \%$ of controls and $39 \%$ of subjects with stroke). Reflective of these differences, joint velocity offset was poorly correlated between elbow and shoulder perturbation trials for both controls $(r=.08, p=0.49)$ and subjects with stroke $(r=.23, p=0.17)$. Further, more subjects $(32 \%)$ were impaired only in response to an elbow or a shoulder load than were impaired in response to both loads (18\%). Percentages were similar when the body weight normative model was applied.
Correlation values between deceleration time and joint velocity offset values were calculated for both stroke and control subgroups to determine if increased joint velocity offset was associated with delayed deceleration times. Deceleration time was moderately correlated to joint velocity offset in control subjects (Pearson correlation; elbow perturbation trials: $r=0.55, p<10^{-6}$; shoulder perturbation trials: $r=0.54, p<10^{-6}$ ) and highly correlated in subjects with stroke (Pearson correlation; elbow perturbation trials: $r=0.74, p<10^{-7}$; shoulder perturbation trials: $r=0.79, p<10^{-8}$ ) (Figure 3f). Therefore, the delayed response of the perturbed joint relative to the unperturbed joint may contribute to delays seen in many subjects with stroke in deceleration time.

Similarly, correlations between maximum displacement and endpoint error were calculated for both stroke and control subgroups to determine if increased maximum displacement was associated with greater endpoint errors. Maximum displacement showed moderate correlation with endpoint error for both controls (Pearson correlation, $r=.74, p<10^{-13}$ ) and subjects with stroke (Pearson correlation, $r=.83, p<10^{-9}$ ) (Figure 3d). Furthermore, all but one of the subjects identified as impaired in maximum displacement also had impaired endpoint errors. Return times for controls and subjects with stroke were also both correlated with their endpoint errors (Pearson correlation, $r=0.87, p<10^{-22}$ and $r=0.53, p<10^{-3}$, respectively). Despite a large number of subjects with stroke being impaired in both parameters, 4 and 5 subjects were identified as being impaired in only return time or endpoint error, respectively (Figure 3e). Therefore, impaired endpoint errors are likely often due to undershooting the target by the end of the trial.

\section{Impairments observed bilaterally}

Subjects with stroke had task-related impairments with their clinically defined unaffected arm. In fact, $63 \%$ of subjects showed longer return times and 55\% showed greater endpoint errors with their 'unaffected' arm than $95 \%$ of controls. On other parameters $26-47 \%$ of subjects

Table 2 Task performance

\begin{tabular}{|c|c|c|c|c|c|c|}
\hline \multirow[t]{2}{*}{ Parameter } & & \multicolumn{2}{|c|}{ LA impaired (\%) } & \multicolumn{2}{|c|}{ RA impaired (\%) } & \multirow{2}{*}{$\begin{array}{l}\text { Interrater } \\
r(p)\end{array}$} \\
\hline & & A arm & $\mathrm{U}$ arm & A arm & $\mathrm{U}$ arm & \\
\hline \multicolumn{2}{|l|}{ Posture speed } & 50 & 41 & 38 & 13 & $.74\left(<10^{-4}\right)$ \\
\hline \multicolumn{2}{|l|}{ Deceleration time } & 91 & 50 & 63 & 44 & $.68\left(<10^{-4}\right)$ \\
\hline \multicolumn{2}{|l|}{ Return time } & 91 & 77 & 63 & 44 & $.91\left(<10^{-11}\right)$ \\
\hline \multicolumn{2}{|l|}{ Endpoint error } & 86 & 68 & 56 & 38 & $.91\left(<10^{-11}\right)$ \\
\hline \multicolumn{2}{|c|}{ Maximum displacement } & 55 & 50 & 31 & 19 & $.97\left(<10^{-14}\right)$ \\
\hline \multirow[t]{2}{*}{ Joint velocity offset } & elbow load & 36 & 32 & 19 & 19 & $.81\left(<10^{-7}\right)$ \\
\hline & shoulder load & 45 & 41 & 25 & 19 & $.74\left(<10^{-6}\right)$ \\
\hline
\end{tabular}

Abbreviations: LA (left affected subjects), $R A$ (right affected subjects), impaired (subjects with stroke whose performance exceeded $95 \%$ of controls on a particular task parameter), A arm (affected arm), $\mathrm{U}$ arm (unaffected arm). 

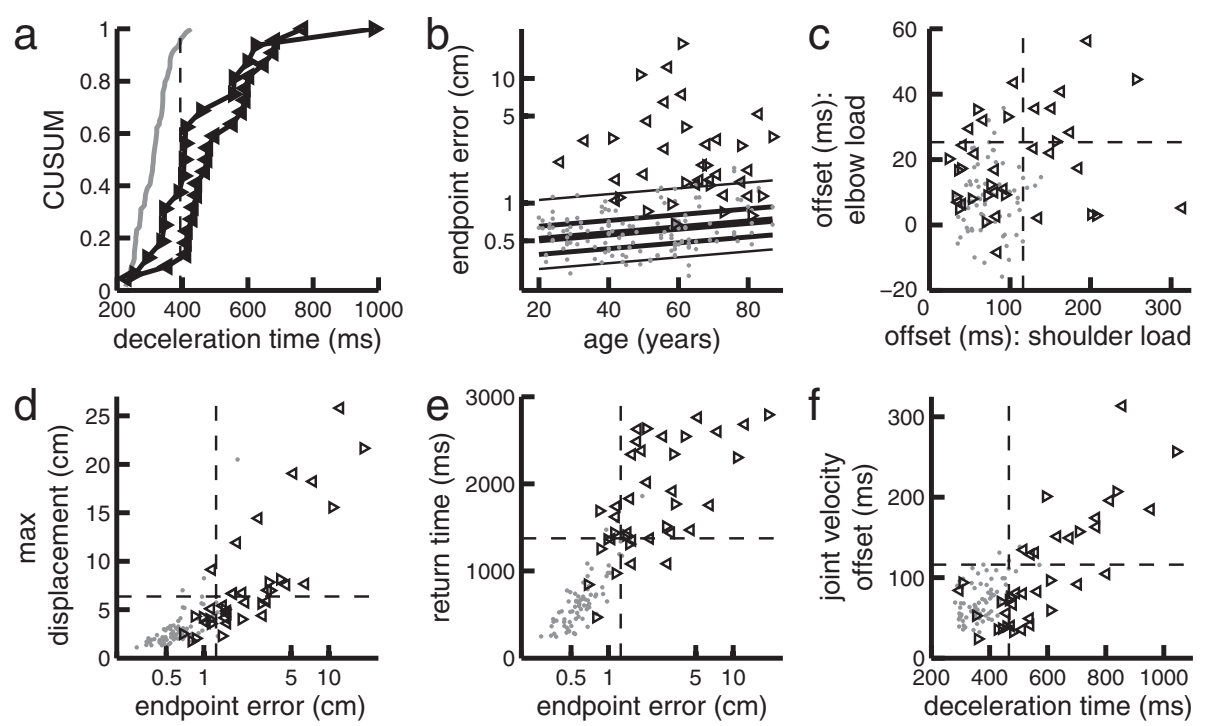

Figure 3 Mean subject performance in task parameters. (a) Cumulative sum distribution for mean deceleration time. Performance by control subjects shown in grey. Performance of the affected arm of subjects with stroke is shown by the leftward and rightward pointing triangles representing left-affected and right-affected subjects, respectively. Dotted line represents 95th percentile for controls. (b) Subject age versus mean endpoint error. Percentile bands of age normative model are the lines (from bottom to top) 5th, 25th, 50th, 75th, and 95th. Note the logarithmic $y$-axis. (c) Mean joint velocity offset during shoulder versus elbow perturbation trials. Note axes are not equally scaled. (d) Mean endpoint error versus maximum displacement. Note axes are not equally scaled and the $x$-axis is logarithmic. (e) Mean endpoint error versus return time. Note the logarithmic x-axis. (f) Mean deceleration time versus joint velocity offset for shoulder load trials.

with stroke exhibited task related impairments with their 'unaffected' arm.

By comparing task performance across arms, we could observe the relative magnitude of impairment in the affected versus unaffected arm (Figure 4). Although a few subjects displayed impairments in only the unaffected arm, these values were very close to $95 \%$ of controls and relate to the tradeoff of sensitivity and specificity in our impairment assignment. Most of the subjects with stroke who were bilaterally impaired in deceleration time, endpoint error, and return time can be seen to have qualitatively similar parameter values when comparing the affected and unaffected arm (Figure 4).

The presence of task impairments in the 'unaffected' arm could reflect our inclusion of subjects with brainstem strokes and subjects with CMSA scores $<7$ on the
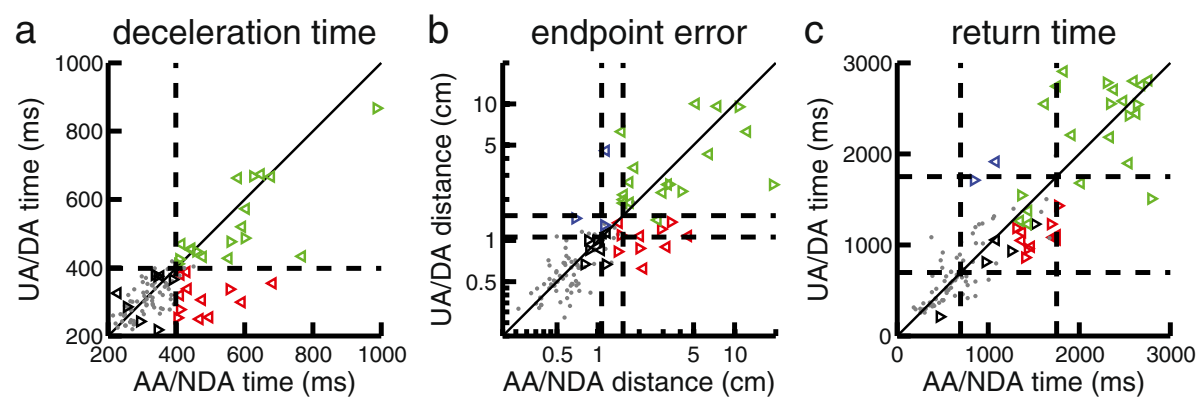

Figure 4 Comparison of mean subject performance in task parameters between arms. (a) Deceleration time. Control subject performance is shown by the grey dots with the $x$-value for the non-dominant arm (NDA) and the $y$-value for the dominant arm (DA). Performance of subjects with stroke is shown by the leftward and rightward facing triangles representing left-affected and right-affected subjects (respectively) with $x$-values for the affected arm (AA) and the $y$-values for the unaffected arm (UA). Subjects with stroke whose performance is above or below the 95th of control performance (dashed lines) for both arms are represented by green or black triangles, respectively. Subjects with stroke who exceeded the 95th of control performance for with their affected or unaffected arms only are represented by red or blue triangles, respectively. (b) Mean endpoint error for both arms. Dashed lines represent the 95th percentile of control performance for the minimum and maximum age according to the age normative model. (c) Mean return time. Dashed lines represent the minimum and maximum possible 95th percentile of control performance as according to the sex specific normative models. 
'unaffected' limb $(\mathrm{n}=23)$ indicating difficulties to perform certain tasks with this limb. However, we found that $40-73 \%$ of subjects with stroke who had a CMSA of 7 for their 'unaffected' limb and did not have a brainstem stroke $(n=15)$ still displayed impairments in their 'unaffected' arm (9 impaired on deceleration time, 6 impaired on endpoint error, and 11 impaired on return time). Qualitatively, the subjects who showed bilateral task impairments displayed a similar degree of symmetrical task performance between arms, regardless of the subgroup to which they belonged.

\section{Interrater reliability of robotic task performance}

Interrater reliability of parameters was evaluated using an intraclass correlation coefficient. Reliability coefficients ranged from 0.68 to 0.97 , indicating good to excellent reliability (see Table 2 ). Lower reliability values were generally associated with parameters that had a relatively small range of values across the control and stroke populations.

\section{Effects of visual feedback on robotic task performance}

All subjects showed smaller endpoint errors when visual feedback was provided (Figure 5a), and 11 subjects with stroke ended their movements outside of the target with visual feedback. However, 17 of those subjects that returned to the target did not stabilize as close to the centre of the target as 95\% of controls. Overall, 77\% of left-affected and $63 \%$ of right-affected subjects with stroke had endpoint error impairments with visual feedback. All 5 subjects with BIT $<130$ and all but two of subjects with visual field deficits had endpoint errors with visual feedback. Once excluded, 67\% of left-affected and $64 \%$ of right-affected subjects with stroke had endpoint error impairments with visual feedback.

The impairments with visual feedback in these subjects could not be explained by strength impairments. Although 10/11 subjects who stabilized outside of the target with their affected arm had some strength impairment, $21 / 27$ of the subjects with stroke who stabilized inside the target also had strength impairments (Figure $5 \mathrm{c}$ ). Also, all subjects who stabilized outside the target with their unaffected arm had strength scores of 19 or $20 / 20$ (Figure 5d).

Greater endpoint errors with visual feedback were correlated with delayed return time for controls $(r=0.32$, $p=0.005$ ), and subjects with stroke (affected arm: $r=0.63$,
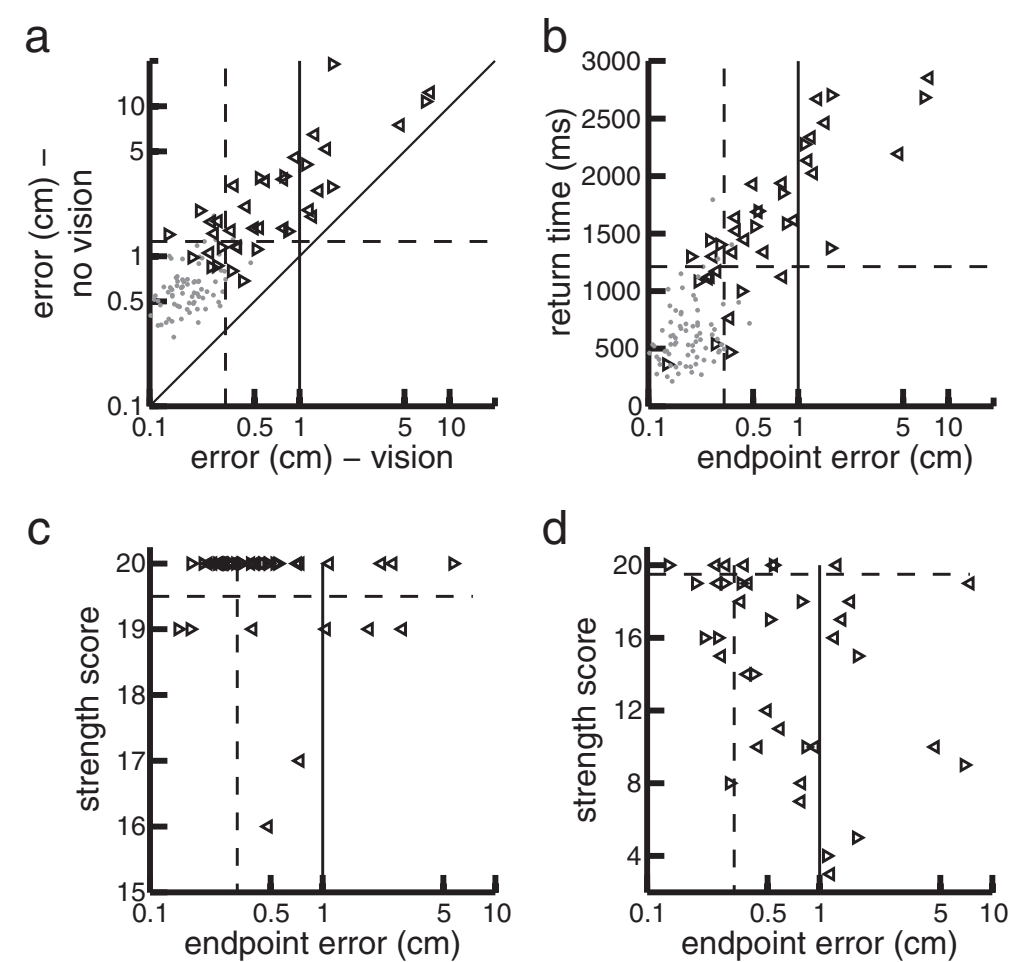

Figure 5 Differences in endpoint error depending on visual feedback condition. (a) Mean endpoint error for trials with hand feedback (vision) compared to trials with no hand feedback (no vision). Performance by control subjects is shown by the grey dots. Stroke performance of the affected arm is shown by the leftward and rightward pointing triangles representing left-affected and right-affected subjects respectively. Dotted line shows 95th percentile of control performance and solid vertical line shows target radius. (b) Mean endpoint error for trials with hand feedback (vision) compared to mean return time for the affected arm. (c) Mean endpoint error for trials with hand feedback (vision) compared to strength scores in the clinically defined affected arm. (d) Same as (c) but for 'unaffected' arm. 
$p<10^{-4}$; unaffected arm: $r=0.70, p<10^{-5}$ ) (Figure 5b). There was no effect of visual feedback manipulations for other task parameters for either controls $(D<.11, p>0.75)$ or subjects with stroke $(D<.19, p>0.49)$ according to paired KS tests.

\section{Relationship between standard clinical assessment measures and task performance}

We expected clinical assessment values to correlate with task performance values for the affected arm and potentially for the unaffected arm. Surprisingly, task performance values from subjects with stroke were not correlated to their scores on clinical scales with their affected arm, but were sometimes correlated to those with their 'unaffected' arm. Specifically, posture speed of the unaffected arm correlated with its CMSA arm subscore $(r=-0.43, p<0.01)$, its strength $(r=-0.55$, $\left.p<10^{-3}\right)$ and the subject's FIM motor subscore $(r=-0.44$, $p<0.01$ ). Also, endpoint error and joint velocity offset for shoulder perturbation trials (with the unaffected arm) significantly correlated with the subject's BIT score ( $r=-0.38, p=0.02$ and $r=-0.36, p=0.03$, respectively). Negative correlations indicated, as expected, that greater parameter abnormality was associated with greater clinical impairment or disability.

\section{Discussion}

Stroke can damage a wide range of brain areas, leading to disruption of many different pathways including those related to somatosensory feedback for motor function. The present study quantified the ability of subjects with subacute stroke to counter mechanical perturbations during postural control of the arm. We found that the majority of subjects with stroke were impaired in a number of parameters as compared to control subjects. Without vision, subjects with stroke commonly displayed slower responses to oppose the load, longer return times or failed to return to the target, and disrupted coordination of the shoulder and elbow. About half of the subjects with stroke that were impaired with their 'affected' arm were also impaired with their 'unaffected' arm. Visual feedback did not improve corrective responses except for endpoint error, although impairments in endpoint error could persist even with visual feedback. Ipsilateral impairments were correlated with clinical measures, indicating bilateral impairments may be associated with greater overall impairments and disability.

\section{Impairments in multi-joint coordination during corrective responses}

The coordination of the elbow and shoulder joints is an important component of voluntary control, as successful motor actions must account for the fact that torque produced at one joint results in an interaction torque at other joints [41]. Healthy subjects can deal with this biomechanical property of a multi-segmented arm generating consistent temporal patterns of joint kinematics during voluntary movements [42-44]. Subjects with stroke often appear to make jerky and uncoordinated movements, and this partially reflects the fact that they have difficulty controlling for interaction torques during reaching movements $[18,32,45]$.

Corrective responses must also deal with the mechanical properties of the limb and display tightly coordinated timing of individual joint kinematics [3]. This requires the integration of proprioceptive information from both the shoulder and elbow to produce the appropriate motor commands to oppose a limb disturbance [9]. Primary motor cortex has been implicated as crucial to this integration of limb feedback for these corrective responses [13]. Therefore, impairments in corrective responses could relate to stroke-related damage of these cortical areas or associated ascending or descending pathways. Subjects with stroke can display abnormal coupling between muscle groups when responding to a perturbation [22]. This is why we also included a jointbased parameter in the present study to quantify specific impairments in coordinating motion at the shoulder and elbow during motor corrections.

The single-joint loads used in the present study required selective increases in motor commands at only one of the two joints. Several subjects (notably left-affected subjects) were identified as impaired in the timing of joint motion during the earliest phase of the corrective response, and in some cases, the impairment was associated with loads at only one of the two joints. However, some subjects with stroke had task impairments in the absence of impairments associated with multijoint coordination. This suggests multiple mechanisms contributing to post-stroke impairments in corrective responses. Future studies are necessary to identify whether subjects with impaired coordination of the two joints during corrective movements also demonstrate impaired coordination during voluntary tasks such as reaching.

\section{Bilateral impairments in corrective motor responses}

A common impact of stroke is impairment in the contralesional limb, but several studies now highlight that impairments can be present in the ipsilesional limb [46-48]. For example, subjects with stroke often display ipsilesional impairments in sensorimotor tasks such as visually-guided reaching [49-55]. In fact, impairments in reaching performance were shown to persist in subjects with subacute stroke even when their ipsilesional clinical scores were normal [56]. Ipsilesional impairments have also been found in online movement adjustments in response to visual perturbations during reaching $[57,58]$. As well, short latency responses to a perturbation applied 
to the ipsilesional arm are attenuated compared to controls [59].

Previous work has shown that long latency responses of the ipsilesional arm can be reduced compared to healthy controls [14] and may not modulate with different types of perturbations [10]. We also found a large proportion of subjects had task-related impairments with their 'unaffected' arm (26-63\% depending on the parameter). Task-related impairments in the 'unaffected' arm were even observed for subjects with CMSA $=7$ for their 'unaffected' arm.

Although ipsilesional deficits in sensory and motor function can exist, such impairments are usually less than those on the contralesional side [60]. Interestingly, we found that impairments in our postural perturbation task were often qualitatively similar for the 'affected' and 'unaffected' arms. Taken together, these results suggest that impairments in corrective responses following stroke are more commonly bilateral than other impairments of voluntary control.

The presence of bilateral deficits in our postural perturbation task seems surprising given that these responses are assumed to be generated by the spinal cord and a relatively simple transcortical circuit involving primary somatosensory cortex, cerebellum and primary motor cortex [12,61-63]. Thus, possible explanations for bilateral deficits include damage to the corticospinal tract fibers that project ipsilaterally to the spinal cord $[49,64]$, or disinhibition of contralateral primary motor cortex: i.e., diaschisis [65-68]. Deficits in multiple aspects of cognitive and perceptual-motor function may also contribute to impairments in generating feedback responses in either or both limbs. It has been shown that apraxia or deficits in visuo-spatial perception are associated with ipsilesional deficits in hand dexterity [69]. Cognitive impairment such as a deficit in attention has global effects that could also lead to bilateral impairments [70-72].

Another possibility is that bilateral impairments may reflect hemispheric specialization such that damage to one hemisphere would impair particular features of motor control in both limbs [46]. Studies of reaching movements post-stroke reveal left-affected subjects had impairments in endpoint accuracy, whereas right affected subjects had impairments in movement trajectory when using either their ipsilesional [53] or contralesional arm [73]. A study requiring online movement adjustments in response to a visual perturbation during reaching found that left-affected subjects displayed delays in initiating corrective responses and both left- and rightaffected subjects displayed large final position errors when using their ipsilesional arm [58]. Endpoint errors were attributed to intersegmental coordination deficits only in right-affected subjects. This supports the idea of the left hemisphere specializing in accounting for intersegmental dynamics and the right hemisphere specializing in controlling position and velocity [47].

Sensory and motor impairments of subjects with stroke tend to be more prevalent in left-affected subjects. Several studies highlight that left-affected subjects tend to more often have impairments in limb motor $[50,54,55,74]$ and proprioceptive function $[38,75]$. We also found subjects who were left-affected had impairments in the unaffected limb more often than right affected subjects. This suggests, in general, a greater role of the right as compared to the left hemisphere for sensory and motor processing [76-78].

Finally, online corrective responses to maintain postural control may require other cortical regions beyond primary somatosensory and primary motor cortices [2]. Recent studies highlight the sophistication of corrective responses of non-disabled humans and that such responses begin during the long-latency time period $[1,79]$. It has been proposed that rapid corrective responses reflect ongoing voluntary control processes, and thus, implicates much broader cortical circuits beyond a simple transcortical pathway [2]. For example, premotor cortex, primary motor cortex, and cerebellum are active for contra-, but also to a certain degree for ipsilateral limb movements [80-83]. Thus, both motor regions may participate in corrective responses of either limb. Therefore a stroke in either of these regions may lead to deficits in both limbs.

Of particular interest is that about half the subjects with impairments were impaired unilaterally and half were impaired bilaterally. Impairments in controlling the ipsilesional arm tended to be similar in magnitude to impairments in controlling the contralesional arm. The presence of distinct patterns of impairments (bilateral and unilateral) may reflect anatomical differences in lesion size and location for each of sub-group, a focus for future studies.

We found significant correlations between corrective responses with the 'unaffected' arm and clinical measures of spatial attention, functional independence, voluntary upper limb control, and strength. This suggests ipsilesional corrective impairments are proportional to overall impairments that impact the ability to function in daily life. It may also relate to the allowed use of the less affected (ipsilesional) arm in many of these clinical assessment measures, such that the test is measuring the ability to compensate with the less affected arm rather than the functional ability of the more affected arm [84]. Future studies can use this posture perturbation task to investigate whether unilateral or bilateral corrective impairments predict differences in recovery trajectories, long-term outcomes, and responsiveness to different rehabilitation therapies. 


\section{Corrective impairments remain with visual feedback}

Limb afferent feedback through cortex can occur in $~ 50$ $60 \mathrm{~ms}[2,12]$. Visual feedback is slower, but can influence motor output after $\sim 100 \mathrm{~ms}$ when visual disturbances are applied [85-87]. As deceleration times associated with countering the applied load were often half a second or more, it seems surprising that visual feedback was not exploited to initiate the motor response. In fact, except for endpoint errors, we found that subjects' performance did not improve when visual feedback was provided during the corrective response. This may relate to the fact that subjects with stroke cannot always correct for post-stroke impairments in limb position sense when provided with visual feedback [88].

Interestingly, $74 \%$ of subjects with stroke had larger endpoint errors than controls with visual feedback. These findings could not be explained by strength impairments as some subjects who scored poorly in strength returned accurately and some subjects who scored perfect or near perfect in strength had large endpoint errors (Figure 5c,d). As well, subjects' unaffected arm did not commonly show strength deficits, but were often also impaired. We also found that greater endpoint errors with visual feedback were correlated with delayed return times. Thus, subjects may have difficulties completing a movement back to the target before the end of the trial. These greater endpoint errors with visual feedback could also reflect attentional problems [70-72], as all 5 subjects with stroke whose BIT score was $<130$ were impaired in this way.

\section{Limitations}

The purpose of the present study was to develop a simple goal-directed task to quantify the ability of subjects to make rapid corrective responses with the upper limb. One limitation of this study is that we did not collect muscle activity to directly measure muscle stretch responses. Subjects were instructed not to co-contract, but some subjects may have had increased muscle activity at perturbation onset. Furthermore, some subjects with stroke may have shown increased resistance to the imposed load due to altered joint stiffness and/or muscle co-activity. As muscle activity was not collected, the direct relationship between altered long latency muscle activity and behavioral responses to a perturbation could not be quantified. We expect that long-latency and potentially later voluntary responses would be reduced in subjects with stroke who had delayed deceleration times in our task. Additionally, subjects with stroke who had bilateral impairments in our task likely have bilateral attenuated long-latency responses, as has been observed previously [14].

A second limitation is the range in time between stroke onset and our clinical and robotic assessments (2 to 50 days). This implies that our sample of subjects with stroke were at different points in their neurological recovery at the time of the assessment. This limitation reflects the inherent variability in the time patients with stroke are admitted for neurorehabilitation at the three facilities in which the study was conducted. One of these facilities moved patients quickly from acute care to rehabilitation while another often did not admit patients to rehabilitation until several weeks post-stroke. As most impairments show some recovery 50 days post-stroke, the incidence of impairments in feedback control of the upper limb may be greater than identified in the present study if subjects were all assessed close to the onset of stroke [89]. We are currently conducting a longitudinal study in which we assess subjects at different time points post-stroke to quantify recovery of feedback control. Nevertheless, even with a cross-sectional design and a range of time post-stroke, the current study still identifies characteristic behavioural impairments in individual subjects with stroke in the use of limb afferent feedback for motor action.

Finally, the definition of impairment based on the 95\% performance of healthy controls will create false positives and false negatives. This cutoff makes the task susceptible to incorrectly identifying a subject as impaired (as 5\% of control subjects are identified as impaired according to the definition), but was selected to balance sensitivity and specificity.

\section{Conclusions}

The present study demonstrates that stroke can alter corrective actions of both contralesional and ipsilesional arms and this may have important implications for functional abilities. When both upper limbs are impaired, every interaction with an unpredictable external environment carries the risk of spilled drinks, objects dropped and failure in other daily tasks. A risk factor for falling post-stroke is the inability to respond to disturbances in the environment such as a perturbation [90]. Appropriate corrective responses of both the upper [91-93] and lower limbs [94-96] are important to reduce the risk and associated injury of falls $[97,98]$. The presence of bilateral impairments in corrective responses may impact the person's ability to use either arm to catch and stabilize oneself. Furthermore, this could reflect a general difficulty in responding to disturbances with both the upper and lower limbs while walking and standing. Task performance with the 'unaffected' arm in the present study correlated with clinical measures of impairment, attention, and functional ability. This may reflect the impact of a person being unable to successfully compensate with the 'unaffected' side in these clinical assessments (as well as in activities of daily living). Rehabilitation strategies may need to enlarge their focus to include the 'unaffected' side for these bilaterally impaired subjects. This enlarged focus would emphasize the importance of 
bimanual rehabilitation strategies to rehabilitate both arms, rather than focusing on using the less affected arm to help the performance of the more affected arm.

\section{Competing interests}

SHS is co-founder and chief scientific officer of BKIN Technologies that commercializes the KINARM robot. Authors TCB, AMC, SDB, SPD, and KEN have no competing interests.

\section{Authors' contributions}

TCB contributed to robotic and clinical data collection, data analysis and interpretation, and drafting of the manuscript. AMC contributed to robotic and clinical data collection. SDB contributed to patient recruitment. SPD contributed to patient recruitment and drafting of the manuscript. KEN contributed to data analysis and interpretation, and drafting of the manuscript. SHS contributed to task design, data analysis and interpretation, and drafting of the manuscript. All authors read and approved the final manuscript.

\section{Acknowledgements}

The authors would like to thanks S Appaqaq, H Bretzke, MJ Demers, M Metzler, K Moore, J Peterson, and J Yajure for their help with data collection, patient recruitment, and technical support. This work was supported by the Ontario Research Fund (ORF-RE 04-47), Canadian Institute of Health Research operating grants (MOP 106662 and MOP 81366), and the Heart and Stroke Foundation of Alberta, Northwest Territories, and Nunavut Grant-In-Aid. SH Scott was supported by a GSK-CIHR chair in Neuroscience.

\section{Author details}

${ }^{1}$ Centre for Neuroscience Studies, Queen's University, Kingston, ON, Canada. ${ }^{2}$ Department of Physical Medicine and Rehabilitation, Queen's University, Kingston, ON, Canada. ${ }^{3}$ Clinical Neurosciences, University of Calgary, Calgary, $A B$, Canada. ${ }^{4}$ School of Rehabilitation Therapy, Queen's University, Kingston, ON, Canada. ${ }^{5}$ Department of Biomedical and Molecular Sciences, Queen's University, Kingston, ON, Canada.

Received: 26 September 2014 Accepted: 13 January 2015

Published: 20 January 2015

\section{References}

1. Pruszynski JA, Scott SH. Optimal feedback control and the long-latency stretch response. Exp Brain Res. 2012;218:341-59.

2. Scott SH. The computational and neural basis of voluntary motor control and planning. Trends Cogn Sci. 2012;16:541-9.

3. Pruszynski JA, Kurtzer I, Scott SH. Rapid motor responses are appropriately tuned to the metrics of a visuospatial task. J Neurophysiol. 2008;100:224-38.

4. Hammond PH. The influence of prior instruction to the subject on an apparently involuntary neuro-muscular response. J Physiol. 1956;132:17-18P.

5. Rothwell JC, Traub MM, Marsden CD. Influence of voluntary intent on the human long-latency stretch reflex. Nature. 1980;286:496-8.

6. Evarts EV, Granit R. Relations of reflexes and intended movements. Prog Brain Res. 1976;44:1-14.

7. Lewis GN, MacKinnon CD, Perreault EJ. The effect of task instruction on the excitability of spinal and supraspinal reflex pathways projecting to the biceps muscle. Exp Brain Res. 2006;174:413-25.

8. Crevecoeur F, Kurtzer I, Bourke T, Scott SH. Feedback responses rapidly scale with the urgency to correct for external perturbations. J Neurophysiol. 2013;110:1323-32.

9. Kurtzer IL, Pruszynski JA, Scott SH. Long-latency reflexes of the human arm reflect an internal model of limb dynamics. Current Biol. 2008;18:449-53.

10. Trumbower RD, Finley JM, Shemmell JB, Honeycutt CF, Perreault EJ. Bilateral impairments in task-dependent modulation of the long-latency stretch reflex following stroke. Clin Neurophysiol. 2013;124:1373-80.

11. Nashed JY, Crevecoeur F, Scott SH. Influence of the behavioral goal and environmental obstacles on rapid feedback responses. J Neurophysiol. 2012;108:999-1009.

12. Matthews PB. The human stretch reflex and the motor cortex. Trends Neurosci. 1991;14:87-91.

13. Scott SH. Optimal feedback control and the neural basis of volitional motor control. Nat Rev Neurosci. 2004;5:532-46.
14. Pruszynski JA, Kurtzer I, Nashed JY, Omrani M, Brouwer B, Scott SH. Primary motor cortex underlies multi-joint integration for fast feedback control. Nature. 2011;478:387-90.

15. Marsden CD, Merton PA, Morton HB, Adam J. The effect of lesions of the sensorimotor cortex and the capsular pathways on servo responses from the human long thumb flexor. Brain. 1977;100:503-26.

16. Lee RG, Tatton WG. Motor responses to sudden limb displacements in primates with specific CNS lesions and in human patients with motor system disorders. Can J Neurol Sci. 1975;2:285-93.

17. Porter R, Lemon R. Corticospinal Function and Voluntary Movement. In: Book Corticospinal Function and Voluntary Movement. Oxford: Clarendon Press; 1993.

18. Teasell R, Hussein N. Clinical Consequences of Stroke. In: Evidence Based Review of Stroke Rehabilitation (www.ebrsr.com). 2013.

19. Twitchell TE. The restoration of motor function following hemiplegia in man. Brain. 1951;74:443-80.

20. Verrier MC, Tatton WG, Blair RD. Characteristics of EMG responses to imposed limb displacement in patients with vascular hemiplegia. Can J Neurol Sci. 1984;11:288-96.

21. Chan CW, Jones GM, Kearney RE, Watt DG. The 'late' electromyographic response to limb displacement in man. I. Evidence for supraspinal contribution. Electroencephalogr Clin Neurophysiol. 1979;46:173-81.

22. Trumbower RD, Ravichandran VJ, Krutky MA, Perreault EJ. Contributions of altered stretch reflex coordination to arm impairments following stroke. J Neurophysiol. 2010;104:3612-24.

23. Levin MF, Dimov M. Spatial zones for muscle coactivation and the control of postural stability. Brain Res. 1997;757:43-59.

24. Schmit BD, Dhaher Y, Dewald JP, Rymer WZ. Reflex torque response to movement of the spastic elbow: theoretical analyses and implications for quantification of spasticity. Ann Biomed Eng. 1999;27:815-29.

25. Sangani SG, Starsky AJ, McGuire JR, Schmit BD. Multijoint reflexes of the stroke arm: neural coupling of the elbow and shoulder. Muscle Nerve. 2007;36:694-703.

26. Sangani SG, Starsky AJ, McGuire JR, Schmit BD. Multijoint reflex responses to constant-velocity volitional movements of the stroke elbow. J Neurophysiol. 2009;102:1398-410.

27. Lin FM, Sabbahi M. Correlation of spasticity with hyperactive stretch reflexes and motor dysfunction in hemiplegia. Arch Phys Med Rehabil. 1999;80:526-30.

28. Bonan IV, Colle FM, Guichard JP, Vicaut E, Eisenfisz M, Tran Ba Huy P, et al. Reliance on visual information after stroke. Part I: Balance on dynamic posturography. Arch Phys Med Rehab. 2004;85:268-73.

29. Piovesan D, Casadio M, Morasso P, Giannoni P. Influence of visual feedback in the regulation of arm stiffness following stroke. Conf Proc. 2011;2011:8239-42.

30. Cluff T, Crevecoeur F, Scott SH. A Perspective on Multisensory Integration and Rapid Perturbation Responses. In: Vision Research. 2014.

31. Gowland C, Stratford P, Ward M, Moreland J, Torresin W, Van Hullenaar S, et al. Measuring physical impairment and disability with the Chedoke-McMaster Stroke Assessment. Stroke. 1993;24:58-63.

32. Brunnstrom S. Motor testing procedures in hemiplegia: based on sequential recovery stages. Phys Ther. 1966:46:357.

33. Compston A. Aids to the investigation of peripheral nerve injuries. Medical Research Council: Nerve Injuries Research Committee. His Majesty's Stationery Office: 1942; pp. 48 (iii) and 74 figures and 7 diagrams; with aids to the examination of the peripheral nervous system. By Michael O'Brien for the Guarantors of Brain. Saunders Elsevier: 2010; pp. [8] 64 and 94 Figures. Brain. 2010;133:2838-44.

34. Keith RA, Granger CV, Hamilton BB, Sherwin FS. The functional independence measure: a new tool for rehabilitation. Adv Clin Rehabil. 1987;1:6-18.

35. Wilson B, Cockburn J, Halligan P. Development of a behavioral test of visuospatial neglect. Arch Phys Med Rehabil. 1987;68:98-102.

36. Oldfield RC. The assessment and analysis of handedness: the Edinburgh inventory. Neuropsychologia. 1971;9:97-113.

37. Scott SH. Apparatus for measuring and perturbing shoulder and elbow joint positions and torques during reaching. J Neurosci Methods. 1999;89:119-27.

38. Dukelow SP, Herter TM, Moore KD, Demers MJ, Glasgow JI, Bagg SD, et al. Quantitative assessment of limb position sense following stroke. Neurorehabil Neural Repair. 2010;24:178-87.

39. Kurtzer I, Pruszynski JA, Scott SH. Long-latency and voluntary responses to an arm displacement can be rapidly attenuated by perturbation offset. J Neurophysiol. 2010;103:3195-204. 
40. Herter TM, Scott SH, Dukelow SP. Systematic changes in position sense accompany normal aging across adulthood. J Neuroeng Rehabil. 2014;11:43.

41. Hollerbach MJ, Flash T. Dynamic interactions between limb segments during planar arm movement. Biol Cybern. 1982;44:67-77.

42. Graham KM, Moore KD, Cabel DW, Gribble PL, Cisek P, Scott SH. Kinematics and kinetics of multijoint reaching in nonhuman primates. J Neurophysiol. 2003;89:2667-77.

43. Dounskaia N. The internal model and the leading joint hypothesis: implications for control of multi-joint movements. Exp Brain Res. 2005;166:1-16.

44. Dounskaia N, Wang W. A preferred pattern of joint coordination during arm movements with redundant degrees of freedom. J Neurophysiol. 2014;112:1040-53.

45. Beer RF, Dewald JP, Rymer WZ. Deficits in the coordination of multijoint arm movements in patients with hemiparesis: evidence for disturbed control of limb dynamics. Exp Brain Res. 2000;131:305-19.

46. Sainburg RL, Duff SV. Does motor lateralization have implications for stroke rehabilitation? J Rehabil Res Dev. 2006;43:311-22.

47. Mutha PK, Haaland KY, Sainburg RL. The effects of brain lateralization on motor control and adaptation. J Mot Behav. 2012;44:455-69.

48. Scott SH, Dukelow SP. Potential of robots as next-generation technology for clinical assessment of neurological disorders and upper-limb therapy. J Rehabil Res Dev. 2011;48:335-53.

49. Desrosiers J, Bourbonnais D, Bravo G, Roy PM, Guay M. Performance of the 'unaffected' upper extremity of elderly stroke patients. Stroke. 1996:27:1564-70.

50. Coderre AM, Zeid AA, Dukelow SP, Demmer MJ, Moore KD, Demers MJ, et al. Assessment of upper-limb sensorimotor function of subacute stroke patients using visually guided reaching. Neurorehabil Neural Repair. 2010;24:528-41.

51. Winstein CJ, Pohl PS. Effects of unilateral brain damage on the control of goal-directed hand movements. Exp Brain Res. 1995;105:163-74.

52. Ketcham CJ, Rodriguez TM, Zihlman KA. Targeted aiming movements are compromised in nonaffected limb of persons with stroke. Neurorehabil Neural Repair. 2007;21:388-97.

53. Schaefer SY, Haaland KY, Sainburg RL. Ipsilesional motor deficits following stroke reflect hemispheric specializations for movement control. Brain. 2007;130:2146-58.

54. Tyryshkin K, Coderre AM, Glasgow Jl, Herter TM, Bagg SD, Dukelow SP, et al. A robotic object hitting task to quantify sensorimotor impairments in participants with stroke. J Neuroeng Rehabil. 2014;11:47.

55. Lowrey C, Jackson C, Bagg S, Dukelow S, Scott S. A novel robotic task for assessing impairments in bimanual coordination post-stroke. Int Phys Med Rehabil S. 2014:3:2

56. Metrot J, Froger J, Hauret I, Mottet D, van Dokkum L, Laffont I. Motor recovery of the ipsilesional upper limb in subacute stroke. Arch Phys Med Rehabil. 2013;94:2283-90.

57. Haaland KY, Prestopnik JL, Knight RT, Lee RR. Hemispheric asymmetries for kinematic and positional aspects of reaching. Brain. 2004;127:1145-58.

58. Schaefer SY, Mutha PK, Haaland KY, Sainburg RL. Hemispheric specialization for movement control produces dissociable differences in online corrections after stroke. Cereb Cortex. 2012;22:1407-19.

59. Thilmann AF, Fellows SJ, Garms E. Pathological stretch reflexes on the "good" side of hemiparetic patients. J Neurol Neurosurg Psychiatry. 1990;53:208-14.

60. Colebatch J, Gandevia S. The distribution of muscular weakness in upper motor neuron lesions affecting the arm. Brain. 1989;112:749-63.

61. Brooks VB. The Neural Basis of Motor Control. New York, New York: Oxford University Press; 1986.

62. Strick PL. The influence of motor preparation on the response of cerebellar neurons to limb displacements. J Neuroscience. 1983:3:2007-20.

63. Hore J, Vilis T. Loss of set in muscle responses to limb perturbations during cerebellar dysfunction. J Neurophysiol. 1984;51:1137-48

64. Noskin O, Krakauer JW, Lazar RM, Festa JR, Handy C, O'Brien KA, et al. Ipsilateral motor dysfunction from unilateral stroke: implications for the functional neuroanatomy of hemiparesis. J Neurol Neurosurg Psychiatry. 2008;79:401-6

65. Nowak DA, Grefkes C, Dafotakis M, Kust J, Karbe H, Fink GR. Dexterity is impaired at both hands following unilateral subcortical middle cerebral artery stroke. Eur J Neurosci. 2007;25:3173-84.

66. Boroojerdi B, Diefenbach K, Ferbert A. Transcallosal inhibition in cortical and subcortical cerebral vascular lesions. J Neurol Sci. 1996;144:160-70.
67. Shimizu T, Hosaki A, Hino T, Sato M, Komori T, Hirai S, et al. Motor cortical disinhibition in the unaffected hemisphere after unilateral cortical stroke. Brain. 2002;125:1896-907.

68. Andrews RJ. Transhemispheric diaschisis. A review and comment. Stroke. 1991;22:943-9.

69. Sunderland A, Bowers MP, Sluman SM, Wilcock DJ, Ardron ME. Impaired dexterity of the ipsilateral hand after stroke and the relationship to cognitive deficit. Stroke. 1999;30:949-55.

70. van Zandvoort MJ, Kessels RP, Nys GM, de Haan EH, Kappelle LJ. Early neuropsychological evaluation in patients with ischaemic stroke provides valid information. Clin Neurol Neurosurg. 2005;107:385-92.

71. Cumming TB, Brodtmann A, Darby D, Bernhardt J. Cutting a long story short: reaction times in acute stroke are associated with longer term cognitive outcomes. J Neurol Sci. 2012;322:102-6.

72. Hyndman D, Pickering RM, Ashburn A. The influence of attention deficits on functional recovery post stroke during the first 12 months after discharge from hospital. J Neurol Neurosurg Psychiatry. 2008;79:656-63.

73. Mani S, Mutha PK, Przybyla A, Haaland KY, Good DC, Sainburg RL. Contralesional motor deficits after unilateral stroke reflect hemisphere-specific control mechanisms. Brain. 2013;136:1288-303.

74. Sterzi R, Bottini G, Celani MG, Righetti E, Lamassa M, Ricci S, et al. Hemianopia, hemianaesthesia, and hemiplegia after right and left hemisphere damage. A hemispheric difference. J Neurology Neurosurg Psychiatr. 1993;56:308-10.

75. Semrau JA, Herter TM, Scott SH, Dukelow SP. Robotic identification of kinesthetic deficits after stroke. Stroke. 2013;44:3414-21.

76. Bowen A, McKenna K, Tallis RC. Reasons for variability in the reported rate of occurrence of unilateral spatial neglect after stroke. Stroke. 1999;30:1196-202.

77. Serrien DJ, Ivry RB, Swinnen SP. Dynamics of hemispheric specialization and integration in the context of motor control. Nat Rev Neurosci. 2006;7:160-6.

78. Kerkhoff G. Spatial hemineglect in humans. Prog Neurobiol. 2001;63:1-27.

79. Nashed JY, Crevecoeur F, Scott SH. Rapid online selection between multiple motor plans. J Neuroscience. 2014;34:1769-80.

80. Cisek P, Crammond DJ, Kalaska JF. Neural activity in primary motor and dorsal premotor cortex in reaching tasks with the contralateral versus ipsilateral arm. J Neurophysiol. 2003;89:922-42.

81. Donchin O, Gribova A, Steinberg O, Bergman H, Vaadia E. Primary motor cortex is involved in bimanual coordination. Nature. 1998:395:274-8.

82. Rijntjes M, Buechel C, Kiebel S, Weiller C. Multiple somatotopic representations in the human cerebellum. Neuroreport. 1999;10:3653-8.

83. Schlerf JE, Verstynen TD, Ivry RB, Spencer RM. Evidence of a novel somatopic map in the human neocerebellum during complex actions. J Neurophysiol. 2010;103:3330-6.

84. Levin MF, Kleim JA, Wolf SL. What do motor "recovery" and "compensation" mean in patients following stroke? Neurorehabil Neural Repair. 2009;23:3139.

85. Pruszynski JA, King GL, Boisse L, Scott SH, Flanagan JR, Munoz DP. Stimuluslocked responses on human arm muscles reveal a rapid neural pathway linking visual input to arm motor output. Eur J Neuroscience. 2010;32:1049-57.

86. Day BL, Lyon IN. Voluntary modification of automatic arm movements evoked by motion of a visual target. Exp Brain Res. 2000;130:159-68.

87. Franklin DW, Wolpert DM. Specificity of reflex adaptation for task-relevant variability. J Neuroscience. 2008;28:14165-75.

88. Herter T, Scott S, Dukelow S. Can Direct Visualization of the Arms Help Compensate for Deficits in Position Sense of the Upper Extremity Following Stroke? In: Stroke; a Journal of Cerebral Circulation. 530 Walnut ST, Philadelphia, PA 19106-3621 USA: Lippincott Williams \& Wilkins; 2012. p. E137-7.

89. Kwakkel G, Kollen B, Lindeman E. Understanding the pattern of functional recovery after stroke: facts and theories. Restor Neurol Neurosci. 2004;22:281-99.

90. Marigold DS, Eng JJ. Altered timing of postural reflexes contributes to falling in persons with chronic stroke. Exp Brain Res. 2006;171:459-68.

91. Mcllroy W, Maki B. Compensatory arm Movements Evoked by Transient Perturbations of Upright Stance. Amsterdam: Vestibular and neural front Elsevier; 1994. p. 489-92.

92. Mcllroy WE, Maki BE. Early activation of arm muscles follows external perturbation of upright stance. Neurosci Lett. 1995;184:177-80.

93. Maki B, Perry SD, Mcllroy WE. Efficacy of handrails in preventing stairway falls: a new experimental approach. Saf Sci. 1998;28:189-206.

94. Horak FB, Nashner LM. Central programming of postural movements: adaptation to altered support-surface configurations. J Neurophysiol. 1986;55:1369-81. 
95. Mcllroy WE, Maki BE. Task constraints on foot movement and the incidence of compensatory stepping following perturbation of upright stance. Brain Res. 1993;616:30-8.

96. Jensen JL, Brown LA, Woollacott MH. Compensatory stepping: the biomechanics of a preferred response among older adults. Exp Aging Res. 2001;27:361-76.

97. Maki BE, Mcllroy WE. Control of rapid limb movements for balance recovery: age-related changes and implications for fall prevention. Age Ageing. 2006;35 Suppl 2:ii12-8.

98. Maki BE, Mcllroy WE. The role of limb movements in maintaining upright stance: the "change-in-support" strategy. Phys Ther. 1997;77:488-507.

doi:10.1186/1743-0003-12-7

Cite this article as: Bourke et al.: Impaired corrective responses to postural perturbations of the arm in individuals with subacute stroke. Journal of NeuroEngineering and Rehabilitation 2015 12:7.

\section{Submit your next manuscript to BioMed Central and take full advantage of:}

- Convenient online submission

- Thorough peer review

- No space constraints or color figure charges

- Immediate publication on acceptance

- Inclusion in PubMed, CAS, Scopus and Google Scholar

- Research which is freely available for redistribution 